\title{
ESTUDOS SOBRE ERGONOMIA E SUAS CONTRIBUIÇÕES AO TRABALHADOR E PARA A ORGANIZAÇÃO
}

\section{ARTIGO DE REVISÃO}

ROCHA, Fernanda Pacheco de Azevedo ${ }^{1}$

SCATOLIN, Henrique Guilherme ${ }^{2}$

ROCHA, Fernanda Pacheco de Azevedo. SCATOLIN, Henrique Guilherme. Estudos sobre ergonomia e suas contribuições ao trabalhador e para a organização. Revista Científica Multidisciplinar Núcleo do Conhecimento. Ano 05, Ed. 03, Vol. 09, pp. 05-17. Março de 2020. ISSN: 2448-0959, Link de acesso: https://www.nucleodoconhecimento.com.br/psicologia/estudos-sobreergonomia

\section{RESUMO}

O presente estudo tem como objetivo principal verificar as contribuições da ergonomia ao contexto organizacional, observando os benefícios físicos, cognitivos dos trabalhadores, bem como a influência na organização empresarial. Deste modo, pretende-se refletir e suscitar se a ergonomia pode contribuir ao ambiente organizacional; quais são estas contribuições; como estas afetam a rotina e o contexto laboral dos trabalhadores. Para tanto, será utilizada como metodologia a revisão de literatura através da qual foram realizados levantamentos de artigos e livros que destacam contextos organizacionais e rotinas laborais dos trabalhadores. Assim, esta pesquisa pretende proporcionar uma reflexão acerca da ergonomia e suas influências na qualidade de vida do trabalhador.

\footnotetext{
${ }^{1}$ Especialista em Psicologia Organizacional e do Trabalho, graduada em Psicologia pela Fundação Hermínio Ometto.

2 Doutor em Psicologia.
} 
Palavras-chave: Ergonomia, organização, trabalhador.

\section{INTRODUÇÃO}

Neste artigo é apresentado uma breve revisão de literatura acerca da ergonomia. Para tanto, tem-se como problema de pesquisa como a ergonomia pode contribuir na vida dos trabalhadores e no ambiente laboral.

Sendo assim, destaca-se que este estudo é altamente relevante para a sociedade, pois pode ser consultado possíveis reflexões sobre as contribuições que a ergonomia pode trazer efetivamente na qualidade de vida dos trabalhadores. Assim, estudos desta natureza são relevantes para a comunidade cientifica, uma vez que podem tanto despertar para observações críticas no que se refere a interação homem $x$ trabalho, além de contribuir nas pesquisas já existentes, como também servir de base e consulta para novas pesquisas.

Deste modo, o presente estudo tem como objetivo principal verificar as contribuições da ergonomia ao contexto organizacional, pesquisando benefícios físicos, cognitivos dos trabalhadores, bem como a influência na organização empresarial. Assim, pretende-se refletir e suscitar se a ergonomia pode contribuir a melhorias no ambiente organizacional; quais seriam estas contribuições; como estas afetariam a rotina e o contexto laboral dos trabalhadores e se proporcionariam, de algum modo, qualidade de vida.

Assim, para melhor compreensão desta temática, cabe explicitar a etiologia da palavra ergonomia: Ergon = trabalho; Nomos = regras, ou seja, trabalho e regras. Assim, Lida (2005) ressalta que ergonomia seria o estudo da adaptação do trabalho ao homem.

A partir deste contexto, este estudo tem como objetivo principal verificar as contribuições da ergonomia ao contexto organizacional, observando os benefícios físicos, cognitivos dos trabalhadores, bem como a influência na organização empresarial e na qualidade de vida do trabalhador. 
A metodologia utilizada neste artigo será a de revisão de literatura. Mancini e Sampaio (2006) definem que revisões da literatura são caracterizadas pela análise e pela síntese da informação disponibilizada por todos os estudos relevantes publicados sobre um determinado tema, de forma a resumir o corpo de conhecimento existente e levar a concluir sobre o assunto de interesse.

\section{REVISÃO DE LITERATURA}

Ao longo da década de 1949, mais especificamente no dia doze de julho de 1949 emerge a ergonomia. Foi exatamente neste dia que se reuniram na Inglaterra, pela primeira vez, um grupo de cientistas e pesquisadores com intenção de dialogar e formalizar a existência desta área de "aplicação interdisciplinar da ciência". Em meados de fevereiro de 1950 ocorreu a segunda reunião, onde foi proposto o neologismo ergonomia. (MURRELL,1965 apud LIDA, 2005).

Assim, como já citado na introdução, no termo ergonomia temos ergon (que significa trabalho) e o termo nomos (que tem como significado regras). A ergonomia pode ter sido reconhecida apenas nesta data especificada, mas a mesma teve um período de "gestação" que faz-nos recordar da sua pré- história, quando um homem escolheu uma pedra que melhor se adaptasse à sua mão e aos movimentos que ele usaria como arma, fazendo com que o instrumento facilitasse tarefas que lhes eram rotineiras como esmagar, cortar e caçar (LIDA, 2005).

Por conseguinte, a ergonomia foi formalizada como ciência no ano de $1950 \mathrm{com}$ a fundação da Ergonomics Research Society, na Inglaterra, na qual diversos pesquisadores iniciaram a difusão de conhecimentos voltados não somente para a aplicação militar, mas também ao contexto industrial como ocorreu em anos anteriores (LIDA, 2005).

Neste sentido, o termo ergonomia foi tomado em países europeus substituindo nomeações como "fisiologia do trabalho e psicologia do trabalho". Assim, na era artesanal havia a preocupação de adaptar as tarefas às condições e necessidades humanas, porém durante o período da Revolução Industrial, ocorrida no século XVIII, 
onde o trabalho nas fábricas era exercido de forma exaustiva e em condições precárias, surgiram muitas barreiras para que esta assistência da fisiologia do trabalho fosse efetivamente aplicada; já que o ambiente era muito diferente de uma fábrica moderna, pois era sujo, barulhento, além do fato de que os trabalhadores exerciam suas atividades por até dezesseis horas por dia, muito semelhante de um regime de "semiescravidão", onde imperavam empresários autoritários, baixíssimos salários, exploração do trabalho infantil, chegando até a usar de castigos corporais (LIDA, 2005).

Até os meados do século XX predominou esta realidade denominada de taylorismo, através do qual se pensava no trabalhador apenas como meio de consumo e produção, onde era levado em consideração apenas a capacidade de seu trabalho físico. Segundo o autor Itiro Lida (2005) a superação do taylorismo nos meados do século XX corroborou para refletir na complexidade do trabalho, de se trabalhar e na multiplicidade de fatores que o compõem.

Neste sentido, de acordo com Clot, (2006, p. 12) "o trabalho não é uma atividade entre outras. Exerce na vida pessoal uma função psicológica específica, que se deve chegar a definir. E isso, precisamente, em virtude de ser ele uma atividade dirigida". Deste modo, torna-se essencial refletir na distinção do que deve ser entendido como tarefa e atividade. Assim, tarefa é aquilo que se pretende fazer, já a atividade é aquilo que é feito.

Para a ergonomia é de extrema importância a compreensão e a diferenciação destes dois termos, já que os mesmos denotam as ações dos trabalhadores, bem como está associado ao reconhecimento da competência do trabalhador.

A propósito, ao falar em ergonomia, Lida (2005) destaca que se trata da adequação do trabalho ao homem, sendo considerado trabalho não somente aquele que envolve máquinas, equipamentos, mas também é de suma importância pensar em trabalho na perspectiva da relação entre o homem e uma ação produtiva, considerando assim o ambiente físico e aspectos organizacionais. 
Wisner (1987) define a ergonomia como "o conjunto de conhecimentos científicos relativos ao homem e necessário para a concepção de ferramentas, máquinas e dispositivos que possam ser utilizados com o máximo de conforto, segurança e eficácia" (WISNER, 1987, p. 12)

Nesta conjuntura, Lida ( 2005) destaca que uma das primeiras definições de ergonomia é a da Ergonomics Society da Inglaterra, uma vez que ergonomia seria "o estudo das interações das pessoas com a tecnologia, a organização e o ambiente, objetivando intervenções que visem melhorar, de forma integrada e não dissociada, a segurança, o conforto, o bem-estar e a eficácia das atividades humanas" (LIDA, 2005, p.5).

Dentre as duas definições é possível observar que ambas definem a ergonomia destacando a interação homem $x$ trabalho, de modo a tornar o ambiente de trabalho, sua organização e equipamentos como aspectos que proporcionem segurança, conforto, bem-estar e eficácia.

Sendo assim, Lida (2005) destaca que o objetivo principal da ergonomia é a transformação do trabalho, adequando-o as capacidades e limitações humanas. $\mathrm{O}$ que se pode salientar é que quando esta adequação não acontece, torna-se intolerável para a ergonomia, pois, entre as consequências destas condições intoleráveis, estão máquinas complexas de operar, condições ruins de trabalho, que acabam causando sacrifícios psicológicos e lesões físicas ao trabalhador.

Assim, a ergonomia trabalha de uma maneira bastante ampla, envolvendo ações de planejamento e projeto, atuando antes, durante e após, ou seja, antes mesmo do trabalho ser realizado, como medida de controle e após como medida de avaliação. Para isto, "os ergonomistas devem analisar o trabalho de forma global, incluindo os aspectos físicos, cognitivos, sociais, organizacionais, ambientais e outros". (LIDA, 2005, p. 3). 
A propósito, torna-se fundamental apresentar os domínios e características especificas que os ergonomistas precisam necessariamente levar em consideração, tais como a ergonomia física, cognitiva e organizacional mencionadas abaixo:

Ergonomia Física - Ocupa-se das características da anatomia humana, antropometria, fisiologia e biomecânica, relacionados com a atividade física. Os tópicos relevantes incluem a postura no trabalho, manuseio de materiais, movimentos repetitivos, distúrbios musculoesqueléticos, relacionados ao trabalho, projeto de postos de trabalho, segurança e saúde do trabalhador.

Ergonomia Cognitiva - Ocupa-se dos processos mentais, como a percepção, memória, raciocínio e resposta motora, relacionados com as interações entre as pessoas e outros elementos de um sistema. Os tópicos relevantes incluem a carga mental, tomada de decisões, interação homem-computador, estresse e treinamento.

Ergonomia Organizacional - Ocupa-se da otimização dos sistemas sócio técnicos, abrangendo as estruturas organizacionais, políticas e processos. Os tópicos relevantes incluem comunicações, projeto de trabalho, programação do trabalho em grupo, projeto participativo trabalho cooperativo, cultura organizacional, organizações em rede, teletrabalho e gestão da qualidade. (LIDA, 2005, p. 3).

Em suma, a ergonomia trabalha a interação homem e seu trabalho como um todo, levando em consideração as características físicas do indivíduo, os processos mentais, assim como as estruturas, políticas e processos organizacionais, sendo todos estes elementos analisados conforme a interação contínua entre si. (LIDA, 2005).

Por conseguinte, falando nos aspectos estudados pela ergonomia, é de fundamental importância ressaltar que cabe ao ergonomia analisar tanto fatores que influenciam no sistema produtivo, como também nas consequências que estas influencias podem 
acarretar ao trabalhador; procurando sempre um modo de reduzir estas consequências, sendo que estas podem ser acidentes, erros, fadiga, estresse, de modo a proporcionar aos trabalhadores satisfação, segurança e saúde na sua interação com o trabalho (LIDA, 2005).

Assim, Wisner (1987), em seu livro Por dentro do Trabalho Ergonomia: Método e Técnica, apresenta "o custo humano do trabalho", o qual está relacionado ao fato de que existem trabalhadores que dependem da profissão de maneira exploratória e, por consequência, acabam sofrendo mais que outros. Ele cita, como exemplo, o servente e o professor, o qual o servente acaba tendo uma expectativa menor de vida, por conta das exposições à fatores de risco que existem em sua função, como maquinário inadequado e a exposição constante aos raios solares, por exemplo, diferente dos fatores de risco de professores, que está relacionado a condições de estresse, além de lesões por esforço repetitivo. O estresse também pode ser desencadeado em profissionais que desempenham atividades braçais, e toda esta problemática e variantes devem ser observadas.

De acordo com Wisner (1987)

Os principais aspectos do custo humano do trabalho são as doenças profissionais e as doenças ligadas ao trabalho, os acidentes, o desgaste e a fadiga, o sofrimento, o desinteresse. As doenças profissionais são aquelas para as quais existe referência na legislação. A "reparação" é submetida a condições precisas e muito restritivas. Um volume muito mais considerável de doenças ligadas ao trabalho não são objeto de reconhecimento legal; no entanto provocam danos e exigem uma ação higiênica e ergonômica. (WISNER, 1987, p. 38)

Assim, as doenças ligadas ao trabalho são aquelas em que a atividade laboral é um fator de risco que desencadeia, contribui e agrava um distúrbio, como lombalgias nos casos de operários de manutenção e lombalgias nos condutores de máquinas. Além do fato dos acidentes de trabalho, que, muitas vezes, acabam colocando em risco a vida dos trabalhadores, e tornam algumas atividades cotidianas angustiantes, certas 
atividades podem causar lesões e ferimentos como cortes, queimaduras, entre outros (WISNER, 1987). Ainda segundo este autor:

O conhecimento preciso dos acidentes por tipo de atividade permite localizar os postos que são fonte habitual e remediá-los. Entretanto, veremos que certas soluções (proteções de máquinas, equipamentos individuais de proteção), não tendo sido acompanhadas de um estudo ergonômico correto, não são compatíveis com o trabalho, com o nível de produção exigido. Nesses casos, a situação é agravada pelo conflito e recomendações de segurança. (WISNER, 1987, p. 39).

A fadiga, o sofrimento no trabalho e o desinteresse acontecem, muitas das vezes, quando o trabalhador se encontra com uma sobrecarga física ou mental. Assim, estudar sobre a carga de trabalho físico e mental é um amplo campo de atuação ergonômica (WISNER, 1987).

Segundo Lida (2005) a ergonomia prioriza a saúde, a segurança e a satisfação do trabalhador. Deste modo, Ferreira (2015) apresenta uma das linhas de estudo da ergonomia, a Analise Ergonômica do Trabalho (AET), a qual estuda o trabalho tanto na dimensão tarefa (aquilo que se pretende fazer) como também na dimensão atividade (aquilo que é realizado); a qual vai pensar o homem em situações concretas de trabalho compreendidas em sua globalidade e complexidade social.

Nesta perspectiva, Ferreira (2015) destaca:

A AET vem contribuindo decisivamente na produção de melhorias que aprimoram os contextos de trabalho, agregando mais segurança, eficiência e eficácia dos processos de trabalho e impactando também no bem-estar dos trabalhadores e na satisfação de usuários e clientes (2015, p. 19)

Tais melhorias contribuem efetivamente para se construir e implantar, juntamente com gestores, trabalhadores e técnicos, medidas que minimizem os problemas que circundam o mundo do trabalho e a vida dos trabalhadores. 
Assim, Rocha (2004) destaca que a revolução social, profissional e cultural que vivemos atualmente corrobora para avanços em recursos tecnológicos com objetivo de facilitar a vida e o dia a dia das pessoas, como telefones, celulares, internet e equipamentos que são lançados constantemente no mercado e que, ao mesmo tempo, contribuem para o aumento de acidentes no trabalho, doenças ocupacionais; o que movimenta várias áreas, como a da saúde social, tecnológica, segurança, entre outras, a discutir e a desenvolver trabalhos voltados a prevenção primária da saúde. Assim:

Fazendo promoção de saúde e proteção especifica, e segurança, bem como do conhecimento e avaliação dos riscos e dos efeitos que os mesmos ocasionam, buscando desta forma uma globalização e padronização de rotinas e práticas que tragam como resultado a proteção à saúde e segurança dos trabalhadores e do meio ambiente, onde criam-se ordens de serviço ou procedimentos específicos e que são exigências legais. (LEI 6.514 - 22.12.1977 - NRS. PORTARIA 3.214 $-08.06 .1978)$.

O que se verifica na vivência e na literatura consultada é que os conflitos de interesses, de classes, sindicatos, órgãos governamentais, convênios médicos, entre outros, demandam altos investimentos e gastos, o que corrobora para o custo do Brasil, onde pode se observar que uma das causas está na "falta de conhecimento técnico, cientifico, administrativo e legal". Nos últimos anos, verifica-se preocupações com a avaliação de riscos correlacionados ao ambiente e as funções de trabalho. Tal preocupação têm se tornado rotina, com o intuito de resolver situações que causam "prejuízos para a empresa e trabalhadores" (ROCHA, 2004, p. 24).

Assim, constata-se que uma avaliação, quando realizada de modo incorreto, acarreta consequências negativas tais como gastos com indenizações, licenças saúde, tratamentos, tanto ao ser humano, quanto as organizações, já que os riscos presentes no ambiente de trabalho acabam afetando os resultados de "segurança, saúde, qualidade e produtividade". (ROCHA, 2004, p. 25). 
Deste modo, cabe aqui ressaltar a importância da fiscalização do Ministério Público do Trabalho, da Delegacia Regional do Trabalho e órgãos municipais do trabalho, para certificar-se de que as medidas de prevenção estão sendo tomadas, e que as Normas Regulamentadoras do Trabalho estão sendo seguidas, já que a ergonomia promove ações fundamentais para a prevenção de passivos ocupacionais, dentre eles: a biomecânica do posto de trabalho, a organização do trabalho, o levantamento e priorização de riscos, e ainda fatores físicos e psicossociais dos trabalhadores, dentre outros. (ROCHA, 2004).

É necessário que se pratique a fiscalização regular e criteriosa, pois a ergonomia quando "consegue" cumprir seu papel na organização, ou seja, quando se consegue colocar em prática todos os benefícios que esta atividade traz aos trabalhadores e às organizações, o que se verifica são colaborações para a estruturação das condições adequadas para o desenvolvimento do trabalho; de forma que estas contribuições conjuminam para que o trabalhador desempenhe suas atividades em segurança, com uma postura adequada, fazendo movimentos pertinentes, e não chegando ao seu limite extremo. Dessa forma, pode-se ter planejamentos para que o ambiente e os equipamentos sejam de fácil acesso, desenvolvendo, consequentemente, treinamentos com a participação dos trabalhadores. Desta forma, todos estes aspectos, quando colocados em ação, atingem diretamente os trabalhadores que irão ter uma interação com seu trabalho "saudável", com o mínimo de riscos possíveis à sua vida e saúde (LIDA, 2005).

Desta forma fica claro que a ergonomia pode estar presente na organização e é de extrema importância aos trabalhadores; por trabalhar com prevenção, promoção e proteção da saúde. As organizações também são beneficiadas economicamente, pois esta prevenção é um combate direto as doenças do trabalho já mencionadas. Consequentemente haverá menos ônus com saúde e processos judiciais, proporcionando funcionários "saudáveis" inseridos em um ambiente com condições adequadas de trabalho. Assim, a necessidade da fiscalização existe, por muitas vezes, uma vez que a organização não apresenta clareza desta relação de custo benefício, o que acarreta a não aplicação (LIDA, 2005). 
Neste sentido, pode-se observar que, no decorrer deste estudo, os benefícios acarretados pela ergonomia, tanto ao trabalhador, assim como para a organização, corroboram para que os trabalhadores tenham uma qualidade de vida e para que as organizações caminhem para a otimização de seus recursos e produtividade. Nesta perspectiva, para compreender a qualidade de vida, é necessário pensar na relação entre o homem, a natureza e o ambiente que ele está inserido, pois nestas três esferas uma exerce influência sobre a outra. (ALMEIDA; GUTIERREZ e MARQUES, 2012). Assim:

Qualidade de vida é uma noção eminentemente humana, que tem sido aproximada ao grau de satisfação encontrado na vida familiar, amorosa, social e ambiental e à própria estética existencial. Pressupõe a capacidade de efetuar uma síntese cultural de todos os elementos que determinada sociedade considera seu padrão de conforto e bem-estar. O termo abrange muitos significados, que refletem conhecimentos, experiências e valores de indivíduos e coletividades que a ele se reportam em variadas épocas, espaços e histórias diferentes, sendo, portanto, uma construção social com a marca da relatividade cultural. (MINAYO et al, 2000, p.10).

Deste modo, pode-se afirmar que o objetivo deste estudo foi atingido, pois, de acordo com o levantamento realizado da literatura correspondente à ergonomia, verificou-se que, quando a ergonomia é efetivamente aplicada em uma organização, onde é possível fazer com que haja participação dos funcionários, interação com gerentes, adequação de equipamentos, influenciado diretamente na organização e nas atividades práticas dos trabalhadores, pode-se afirmar que esta promove bem estar e conforto aos trabalhadores, contribuindo, neste sentido, para que eles tenham uma boa qualidade de vida, com rendimento satisfatório do trabalho e menos afastamento para tratamentos de saúde.

Destaca-se que, ao falar em qualidade de vida, é necessário ressaltar que este é um tema bastante abrangente e que envolve vários aspectos como questões subjetivas, culturais, de moradia, alimentação, saúde, entre outros. Assim, a pretensão deste 
estudo não é apresentar a qualidade de vida em todas as suas especificidades, mas sim, como já apresentado, demonstrar o quanto os trabalhadores podem ter uma boa qualidade de vida, quando estão inseridos num ambiente de trabalho com aplicação da ergonomia que leve em consideração principalmente, seus aspectos físicos e cognitivos. (ALMEIDA; GUTIERREZ e MARQUES, 2012).

\section{CONCLUSÃO}

Portanto, mediante a revisão de literatura realizada neste estudo, foi possível verificar que a ergonomia está presente na humanidade desde a época da pré-história, onde o homem escolheu como ferramenta a pedra que melhor se adaptou à sua mão e aos movimentos das atividades de caça executadas por ele.

Assim, compreende-se que a ergonomia é de extrema relevância ao pensar na transformação do trabalho, proporcionando adequações nas atividades laborais de modo que atendam as condições e necessidades humanas. Vale ressaltar que este tipo de cuidado e planejamento das ações do trabalho eram inimagináveis há décadas atrás, já que o ambiente de trabalho era bastante inadequado, barulhento, momento este em que se trabalhava por várias horas seguidas, ocasionando esgotamento aos trabalhadores.

Refletir sobre todas as transformações que a ergonomia proporciona na execução das atividades laborais de qualquer natureza é muito importante para toda sociedade, uma vez que todas estas mudanças contribuem para a construção, aplicação e reavaliação de normas regulamentadoras que demonstram como o trabalho deve ser executado de forma segura e saudável.

Deste modo, a ergonomia é uma área de aplicação que contribui para o bem-estar do trabalhador, para a sua saúde, segurança e satisfação dos trabalhadores. Nesta perspectiva, este artigo conclui que, se a ergonomia consegue cumprir seu papel diante dos desafios que enfrentamos no mundo laboral, esta pode contribuir significativamente para uma boa qualidade de vida dos trabalhadores. Enfim, cabe destacar aqui que esta pesquisa é apenas o início para leituras complementares, que 
possam contribuir para o desenvolvimento de estratégias contemporâneas para o cuidado e bem-estar no trabalho; sendo um incentivo para novas descobertas na área.

\section{REFERÊNCIAS}

ALMEIDA, Marco Antonio Bettine de; GUTIERREZ, Gustavo Luis; MARQUES, Renato. QUALIDADE DE VIDA: DEFINIÇÃO, CONCEITOS E INTERFACES COM OUTRAS ÁREAS DE PESQUISA. São Paulo: Escola de Artes, Ciências e Humanidades - Each/usp, 2012. 142 p.

CLOT, Y. A função psicológica do trabalho. Petrópolis: Vozes, 2006. - Cap. 2: A Função Psicológico da Trabalho.

(2010). A Psicologia do Trabalho na França e a Perspectiva da Clínica da Atividade. Revista de Psicologia, n.1, p. 207-234.

FERREIRA, Mário César. Ergonomia da Atividade aplicada à Qualidade de Vida no Trabalho: lugar, importância e contribuição da Análise Ergonômica do Trabalho (AET). Rev. bras. Saúde ocup. São Paulo, v. 40, n. 131, p. 18-29, jun. 2015 . Disponível em <http://www.scielo.br/scielo.php?

LIDA, Itiro. Ergonomia Projeto e Produção. 2. ed. São Paulo: Blucher, 2005. 614 p. MANCINI, Marisa Cotta and SAMPAIO, Rosana Ferreira. Quando o objeto de estudo é a literatura: estudos de revisão. Rev. Bras. fisioter. [Online]. 2006, vol.10, n.4. Disponível em < http://dx.doi.org/10.1590/S1413-35552006000400001>. Acesso em 16 jul. 2017.

MINAYO, M. C. S.; HARTZ, Z. M. A.; BUSS, P. M. Qualidade de Vida e saúde: um debate necessário. Ciência \& Saúde Coletiva. Rio de Janeiro, v. 5, n.1, 2000, p. 718. 
ROCHA, Geraldo Celso. Trabalho, Saúde e Ergonomia: Relação entre Aspectos legais e Médicos. Curitiba: Juruá Editora, 2008. $151 \mathrm{p}$

WISNER, Alain. A inteligência no trabalho: textos selecionados de ergonomia. Trad. Roberto Leal Ferreira. São Paulo: Fundacentro, 1994.

WISNER, Alain. Por dentro do Trabalho. Ergonomia: método e técnica. Trad. Flora Maria Gomide Vezzá. São Paulo: FTD/Oboré, 1987.

Enviado: Setembro, 2019.

Aprovado: Março, 2020. 